\title{
Dietary Supplements Contribute Substantially to the Total Nutrient Intake in Pregnant Norwegian Women
}

\author{
Margaretha Haugen Anne Lise Brantsæter Jan Alexander \\ Helle Margrete Meltzer \\ Department of Food Safety and Nutrition, Division of Environmental Medicine, Norwegian Institute of \\ Public Health, Oslo, Norway
}

\section{Key Words}

Dietary supplements • Pregnancy • Nutrient intake •

Multivitamins - Minerals $\cdot$ Fatty acids $\cdot$ Vitamin D - Folate • lodine

\begin{abstract}
Background: Use of dietary supplements during pregnancy may give an important contribution to nutrient intake, and for nutrients like folate and vitamin D supplements are recommended. Our objective was to study use and contribution of dietary supplement to nutrient intake among women participating in the Norwegian Mother and Child Cohort Study (MoBa). Methods: This study is based on 40,108 women participating in MoBa which is conducted by the Norwegian Institute of Public Health. The women had filled inversion 2 of the food frequency questionnaire in MoBa between February 2002 and February 2005. Results: $81 \%$ reported use of one or more dietary supplements. The most commonly used category was cod liver oil/fish oil supplements (59\%) followed by singular folic acid supplements (36\%) and multivitamin/multimineral supplements (31\%). The nutrient contribution of the dietary supplements varied from $65 \%$ for folate and vitamin D to $1 \%$ for potassium among supplement users. The dietary intake of vitamin D, folate, iodine and iron did not reach the Nordic Recommendations for pregnant women. Conclusions: Use of
\end{abstract}

supplements improved the intake of folate, iron and vitamin $D$, but not sufficiently to reach the recommended amounts.

Copyright $\odot 2008$ S. Karger AG, Basel

\section{Introduction}

Epidemiological studies show that nutrition during pregnancy influences fetal growth, development and the risk of various diseases later in life, as well as the well-being of the mother [1-5]. Accordingly, the mother's diet during pregnancy is attracting increased interest. Intake of vitamin and mineral supplements may give an important contribution to nutrient intake. However, beneficial health effects of nutrient supplementation in well-nourished pregnant populations are only documented for folate supplementation in the prevention of neural tube defects [6] and for iron in the prevention of anemia [7]. Lately, attention has been given to $n-3$ fatty acids during pregnancy and lactation, and this has been studied with respect to duration of gestation, infant size at birth, preeclampsia, depression, and infant cognitive and visual function [8-10]. Antioxidant supplementation has been investigated to study the impact on hypertensive disorders and other adverse pregnancy outcomes; however, without convincing risk-reducing effects $[11,12]$.

\section{KARGER}

Fax +41613061234 E-Mail karger@karger.ch www.karger.com
(C) 2008 S. Karger AG, Basel

0250-6807/08/0524-0272\$24.50/0

Accessible online at:

www.karger.com/anm
Margaretha Haugen

Department of Food Safety and Nutrition, Division of Environmental Medicine

Norwegian Institute of Public Health, PO Box 4404

NO-0403 Oslo (Norway)

Tel. + 47210765 63, Fax +47 210762 43, E-Mail margaretha.haugen@fhi.no 
The prevalence and pattern of dietary supplement use have been described in several pregnancy populations [13, 14], but the actual calculated micronutrient contribution from dietary supplements is rarely reported. The collection of data on dietary supplement use is challenging, time-consuming and expensive, but necessary if the true picture of nutrient intake is to be estimated [15]. In the Norwegian Mother and Child Cohort Study (MoBa), which aims to include 100,000 pregnancies by 2008 [16], a database containing details of the declared content of supplements was developed to be able to calculate the contribution of micronutrients and fatty acids from dietary supplements. This is the first study to present micronutrient and fatty acid intakes calculated by the use of this database.

The aim of this study was threefold: (a) to report on dietary supplement use among women participating in $\mathrm{MoBa}$; (b) to evaluate the contribution of these dietary supplements to the total vitamin, mineral and fatty acid intake and (c) to compare the total intake of vitamins and minerals with the Nordic Nutrition Recommendations (NRR) [17].

\section{Materials and Methods}

This study is based on MoBa conducted by the Norwegian Institute of Public Health using version 2 of the quality-assured data files (released April 2006) [16]. In brief, MoBa is a pregnancy cohort started in 1999, with the aim of including 100,000 pregnant women by 2008. The majority of all pregnant women in Norway are invited to participate, and the mean response rate was $41.6 \%$ in 2002-2005. Pregnant women are recruited to the study through a postal invitation in connection with a routine ultrasound examination offered to all pregnant women in Norway at 17-18 weeks of gestation (www.fhi.no/morogbarn). The current study is based on participants recruited between February 2002 and February 2005. Informed consent was obtained from each participant before the study. The regional Committee for Medical Research and the Norwegian Data Inspectorate have approved the study.

\section{Available Dietary Information}

40,817 women, who had answered version 2 of the food frequency questionnaire (FFQ) from February 2002 until February 2005, were eligible to be included in this study. Version 2 of the FFQ has been validated both with regard to diet [18] and dietary supplements [19]. The women answered the FFQ in week 17-24 of the pregnancy and were asked to report on their dietary intake since they became pregnant. To be included in this study, the women had to have a calculated energy intake from the diet higher than 1,070 $\mathrm{kcal}(4,500 \mathrm{~kJ})$ and less than 4,760 kcal (20,000 kJ) [20]. This resulted in a final number of 40,108 (98\%) included pregnancies. The FFQ is semi-quantitative and designed to capture dietary habits and use of supplements. It is described in detail in Meltzer et al. [20]. Altogether, the women answered 263 questions about 255 different food items. For each food question the frequency of use was re- ported by selecting one out of eight to ten frequencies ranging from never to several times monthly, weekly or daily. In addition, global questions were asked regarding hot meals, fruits and vegetables, and these were used for scaling adjustments. Where portion sizes were not given in the questionnaire, consumption frequencies were converted into food amounts by use of standard Norwegian portion sizes for women. The questionnaires were optically read and energy and nutrient intake was calculated with use of FoodCalc [21] and the Norwegian food composition table [22].

\section{Available Information on Dietary Supplement Use}

The last page in the FFQ contains questions about use of food supplements. Thirteen commonly used vitamin, mineral and cod liver oil/fish oil supplements were pre-coded and followed by 6 open-ended spaces where the women were asked to record the name and manufacturer of supplement(s) used but not listed. The frequency was reported as one of 9 options of weekly use (never, $<1$ and 1-7), and the quantity was reported as one of 3 options for liquid supplements and one of 4 options for number(s) of tablets/ capsules $(1,2,3$, and $4+)$.

For nutrient calculation of the dietary supplements, an Access database (Microsoft Office 2003) containing the nutrient value of more than 1,000 different food supplements, was constructed and continuously updated. A data program connected to the Access database read all food supplements recorded by the women and unknown supplements had to be registered and continuously added to the database. Beta-carotene given in $\mu \mathrm{g}$ was converted to retinol equivalents in $\mu \mathrm{g}$ by dividing by 6 . Commonly sold food supplements in Norway were registered by information provided by the manufacturer, whereas nutritional information of dietary supplements bought from the internet or abroad were collected from the internet, either found on the homepage of the manufacturer or the supplier.

To evaluate nutrient intake among the women, the NNR for pregnant women were used [17]. These differ with regard to Recommended Dietary Allowances (RDAs) for USA by higher recommendations for vitamin D, $10 \mu \mathrm{g} /$ day (NNR) and $5 \mu \mathrm{g} / \mathrm{day}$ (RDA), and lower recommendations for folate, $500 \mu \mathrm{g} / \mathrm{day}$ (NNR) and $600 \mu \mathrm{g} / \mathrm{day}(\mathrm{RDA})$, and iodine $175 \mu \mathrm{g} / \mathrm{day}$ (NNR) and 220 $\mu \mathrm{g} / \mathrm{day}(\mathrm{RDA})$.

\section{Statistics}

Age and BMI were normally distributed, whereas the intake of most nutrients was skewed. Normally distributed variables are presented as mean (SD) and nutrient intake variables as both mean (SD) and median, 5th percentile and 95th percentile. Imputation of supplement use was performed when a woman had recorded a frequency but not an amount. The smallest amount was used; i.e. 1 tea spoon, 1 capsule or 1 tablet. Imputation was carried out in $1-5 \%$ of the cases for different supplements. To compare between supplement users and nonusers, independent $t$ test was used for continuous normally distributed variables, and the Mann-Whitney $U$ test was used for skewed data. The $\chi^{2}$ test was used for nominal variables. Logistic regression with supplement use as a dependent variable was used to evaluate impact of the independent factors age, pre-pregnant BMI, education, parity and smoking. All independent factors were put into the model as categorical variables. Statistical significance was considered when $\mathrm{p}$ was $<0.05$. All statistical analyses were performed with the Statistical Package for the Social Sciences software 14.0 (SPSS, Chicago, Ill., USA). 
Table 1. Characterization of dietary supplement users (SUs) and nonusers (NSUs) during the first 4 moths of pregnancy in $\mathrm{MoBa}$

\begin{tabular}{|c|c|c|c|c|}
\hline & $\mathrm{SU}(\mathrm{n}=32,653)$ & $\mathrm{NSU}(\mathrm{n}=7,455)$ & $\begin{array}{l}\mathrm{p} \text { (SU vs. NSU } \\
\text { unadjusted) }\end{array}$ & $\begin{array}{l}\operatorname{Exp}(B)(S U \text { vs. } \\
\text { NSU adjusted })^{1}\end{array}$ \\
\hline Age, years & $29.7 \pm 4.5$ & $29.2 \pm 4.8$ & $<0.001$ & $1.04(1.03,1.05)$ \\
\hline \multicolumn{5}{|l|}{ Age in categories } \\
\hline$<20$ & $336(1.1)$ & $158(2.2)$ & $<0.001$ & $0.72(0.6,0.91)$ \\
\hline $20-24.9$ & $3,520(11.2)$ & $1,074(14.9)$ & $<0.001$ & 1 \\
\hline $25-29.9$ & $11,464(36.4)$ & $2,452(34.1)$ & $<0.001$ & $1.12(1.16,1.39)$ \\
\hline $30-34.9$ & $11,716(37.2)$ & $2,553(35.5)$ & $<0.01$ & $1.41(1.28,1,55)$ \\
\hline$\geq 35$ & $4,488(14.2)$ & $957(13.3)$ & $<0.05$ & $1.66(1.48,1.87)$ \\
\hline Missing & $1,129(3.5)$ & $261(3.5)$ & - & \\
\hline BMI prior to pregnancy & $24.0 \pm 4.2$ & $25.1 \pm 4.8$ & $<0.05$ & $1.00(0.99,1.00)$ \\
\hline \multicolumn{5}{|l|}{ BMI in categories } \\
\hline$<20$ & $3,812(11.7)$ & $637(8.5)$ & $<0.001$ & $1.23(1.11,1.35)$ \\
\hline $20-24.9$ & $17,355(53.1)$ & $3,366(45.2)$ & $<0.001$ & 1 \\
\hline $25-29.9$ & $6,709(20.5)$ & $1,842(24.7)$ & $<0.001$ & $0.76(0.71,0.81)$ \\
\hline $30+$ & $2,897(8.9)$ & $1,064(14.3)$ & $<0.001$ & $0.62(0.57,0.68)$ \\
\hline Missing & $1,880(5.8)$ & $546(7.3)$ & - & \\
\hline \multicolumn{5}{|l|}{ Smoking during pregnancy } \\
\hline Daily & $1,710(5.5)$ & $849(11.9)$ & $<0.001$ & $0.57(0.52,0.63)$ \\
\hline Occasional & $905(2.9)$ & $315(4.4)$ & $<0.001$ & $0.69(0.60,0.79)$ \\
\hline Nonsmokers & $28,720(91.7)$ & $5,967(83.7)$ & $<0.001$ & 1 \\
\hline Missing & $1,318(4.0)$ & $324(4.4)$ & - & \\
\hline \multicolumn{5}{|l|}{ Parity } \\
\hline 0 & $14,913(47.3)$ & $2,505(34.8)$ & $<0.001$ & 1 \\
\hline 1 & $10,966(34.8)$ & $2,836(39.4)$ & $<0.001$ & $0.59(0.55,0.63)$ \\
\hline 2 & $4,603(14.6)$ & $1,431(19.9)$ & $<0.001$ & $0.47(0.43,0.51)$ \\
\hline 3 and more & $1,044(3.3)$ & $424(5.9)$ & $<0.001$ & $0.38(0.40,0.43)$ \\
\hline Missing & $1,127(3.5)$ & $259(3.5)$ & - & \\
\hline \multicolumn{5}{|l|}{ Education } \\
\hline$\leq 9$ years & $1,073(3.5)$ & $501(7.2)$ & $<0.001$ & 1 \\
\hline 10-12 years & $10,185(33.0)$ & $3,335(47.6)$ & $<0.001$ & $1.18(1.04,1.34)$ \\
\hline $13-16$ years & $13,473(43.7)$ & $2,364(33.8)$ & $<0.001$ & $1.86(1.63,2.12)$ \\
\hline$>16$ years & $6,092(19.8)$ & 803 (11.5) & $<0.001$ & $2.26(1.95,2.61)$ \\
\hline Missing & $1,830(5.6)$ & $452(6.1)$ & - & \\
\hline
\end{tabular}

Figures in parentheses indicate percentages or 95\% CI. Values for age and BMI prior to pregnancy are expressed as mean $\pm \mathrm{SD}$.

${ }^{1}$ All variables were mutually adjusted for each other.

\section{Results}

Totally, 32,653 (81.4\%) of the included women registered use of one or more food supplements in the first 4-5 months of their pregnancy. Supplement users were significantly older, had a lower BMI, had longer education, and were more often nonsmoking and primiparous compared to supplement nonusers (table 1). These results were consistent in the adjusted analyses, demonstrating an increased use with age and education level and reduced use with increasing BMI and parity. Among wom- en with a BMI $>30$, dietary supplements were used by $73 \%$ of the population, being significantly lower than in normal weight women where $84 \%$ recorded use of dietary supplements $(\mathrm{p}<0.001)$. The recorded weight gain during the first 3-4 months of pregnancy did not affect dietary supplement use when put into the adjusted model. Median weight gain was $3 \mathrm{~kg}$ in both groups.

$22 \%$ of the women reported use of one supplement, $26.8 \%$ reported use of two different supplements and as many as $32.6 \%$ of the women used 3 or more different supplements. The most frequently used supplements were 
cod liver oil/fish oil, i.e. long chain n-3 fatty acids (table 2). $18.8 \%$ reported use of more than one brand of $n-3$ fatty acid supplements. Among women with BMI $>30$, cod liver oil/fish oil were recorded by $22 \%$, which was a significantly lower prevalence than in normal-weight women where $62 \%$ used cod liver/fish oil ( $p<0.001$ ). Pregnant women used n-3 fatty acid supplements more

Table 2. Type of supplements in the first 4-5 months of pregnancy as reported by 40,108 women participating in $\mathrm{MoBa}$

\begin{tabular}{lc}
\hline $\mathrm{n}-3$ fatty acids (cod liver oil/fish oil) & $23,615(58.6 \%)$ \\
Folic acid & $14,259(35.6 \%)$ \\
Multivitamins and minerals & $12,351(30.8 \%)$ \\
Iron tablets/formulation & $8,668(21.6 \%)$ \\
Multivitamins & $5,648(16.3 \%)$ \\
Pregnancy formulations & $1,888(4.7 \%)$ \\
Calcium tablets & $1,273(3.2 \%)$ \\
Herb supplements & $871(2.1 \%)$ \\
\hline
\end{tabular}

frequently than folic acid as a single supplement. However, folic acid was present in most of the multivitamin and multivitamin-mineral supplements, adding up to folic acid supplementation in $61 \%$ of the women. Folic acid supplementation was used by $56 \%$ of women with a BMI $>30$, which was significantly lower than the $63 \%$ among normal-weight women $(\mathrm{p}<0.05)$.

Table 3 shows the contribution of supplements to nutrient intake among the women who used supplement(s). With use of supplements, the median intake of vitamin $\mathrm{D}$, folate, iron and iodine reached the Nordic recommendations for pregnant women. Supplements provided more than $50 \%$ of the total intake of vitamin $\mathrm{D}$, docosahexaenoic acid (DHA), eicosapentaenoic acid (EPA), vitamin $\mathrm{B}_{6}$, folate, copper and iron, but less than $20 \%$ of the total amount of n-3 fatty acids, magnesium and calcium (fig. 1).

Nutrient intake from food differed between supplement users and non users. Nonusers had significantly lower intake of energy, protein, monounsaturated fat, fi-

Table 3. Daily intake of nutrients from supplements alone and the total intake from diet and supplements among users

\begin{tabular}{|c|c|c|c|c|c|}
\hline & \multirow[t]{2}{*}{ Subjects, n (\%) } & \multicolumn{2}{|l|}{ Supplements } & \multicolumn{2}{|c|}{ Diet plus supplements } \\
\hline & & mean (SD) & median (P5, P95) & mean $(\mathrm{SD})$ & median (P5, P95) \\
\hline Energy, kcal & $23,899(60)$ & $35(39)$ & $15(3,108)$ & $2,371(612)$ & $2,291(1,510,3,520)$ \\
\hline $\mathrm{EPA}, \mathrm{g}$ & $23,503(59)$ & $0.41(0.44)$ & $0.21(0.03,1.24)$ & $0.58(1.05)$ & $0.40(0.09,1.47)$ \\
\hline DHA, g & $23,510(59)$ & $0.47(0.49)$ & $0.23(0.04,1.44)$ & $0.75(0.95)$ & $0.53(0.15,1.81)$ \\
\hline$n-3$ fatty acids, $g$ & $23,761(59)$ & $1.09(1.11)$ & $0.51(0.08,2.88)$ & $3.21(2.14)$ & $2.87(1.33,5.91)$ \\
\hline Retinol, $\mu \mathrm{g}$ & $27,428(68)$ & $570(495)$ & $428(70,1,390)$ & $1,450(830)$ & $1,285(500,2,990)$ \\
\hline Beta-carotene, $\mu \mathrm{g}$ & $2,147(5.4)$ & $2,910(5,920)$ & $1,500(120,9,000)$ & $5,575(6,205)$ & $4,120(1,600,12,400)$ \\
\hline Retinol eq., $\mu \mathrm{g}$ & $28,005(70)$ & $600(930)$ & $430(71,1,400)$ & $1,905(975)$ & $1,715(780,3,630)$ \\
\hline Vitamin $D, \mu g$ & $28,327(71)$ & $10.1(9.3)$ & $6.8(1.1,29.0)$ & $13.6(9.7)$ & $10.4(3.5,32.6)$ \\
\hline Vitamin E, mg & $28,543(71)$ & $14(19)$ & $10(1,36)$ & $25(20)$ & $21(9,49)$ \\
\hline Thiamine, mg & $17,838(44)$ & $2.4(10.4)$ & $1.3(0.2,3.6)$ & $3.9(10.5)$ & $2.7(1.5,5.3)$ \\
\hline Riboflavin, mg & $17,848(44)$ & $2.5(10.4)$ & $1.4(0.2,4.0)$ & $4.5(10.5)$ & $3.3(1.7,6.4)$ \\
\hline Niacin, mg & $16,907(42)$ & $15.8(16.9)$ & $15.0(1.7,36.0)$ & $46.4(18.4)$ & $43.8(28.5,69.9)$ \\
\hline Folate, $\mu \mathrm{g}$ & $24,611(61)$ & $340(250)$ & $400(29,700)$ & $615(270)$ & $607(265,1,027)$ \\
\hline Vitamin $B_{12}, \mu g$ & $14,298(36)$ & $8.4(48.0)$ & $2.0(0.3,13.0)$ & $13.8(38.0)$ & $8.5(3.9,21.7)$ \\
\hline Vitamin $\mathrm{B}_{6}, \mathrm{mg}$ & $17,928(45)$ & $3.1(11.0)$ & $2.0(0.2,5.7)$ & $4.6(11.0)$ & $3.3(1.6,7.3)$ \\
\hline Vitamin $\mathrm{C}, \mathrm{mg}$ & $18,082(45)$ & $79(96)$ & $60(9,200)$ & $246(133)$ & $218(106,468)$ \\
\hline Calcium, mg & $4,439(11)$ & $290(290)$ & $200(4,1,000)$ & $1,270(483)$ & $1,192(631,2,143)$ \\
\hline Magnesium, mg & $8,428(21)$ & $87(89)$ & $75(11,214)$ & $490(149)$ & $467(301,754)$ \\
\hline Potassium, $g$ & $551(1.4)$ & $0.08(0.1)$ & $36(4,360)$ & $4.1(0.1)$ & $4.0(2.56 .2)$ \\
\hline Iron, mg & $19,006(47)$ & $29.0(44.0)$ & $14.0(2.5,109.0)$ & $40.4(44.1)$ & $25.1(12.6,119.7)$ \\
\hline Zinc, mg & $12,470(31)$ & $11.1(8.5)$ & $10.0(1.7,24.9)$ & $22.5(9.0)$ & $21.5(11.9,35.6)$ \\
\hline Copper, mg & $10,887(27)$ & $1.5(1.2)$ & $1.5(0.3,2.9)$ & $2.9(1.2)$ & $2.8(1.5,4.5)$ \\
\hline Iodine, $\mu \mathrm{g}$ & $11,951(30)$ & $105(82)$ & $75(13,225)$ & $237(104)$ & $224(103,415)$ \\
\hline Selenium, $\mu g$ & $12,260(31)$ & $54(41)$ & $50(11,104)$ & $108(44)$ & $102(60,170)$ \\
\hline
\end{tabular}

Dietary folate is calculated according to Yates et al. [43]. 

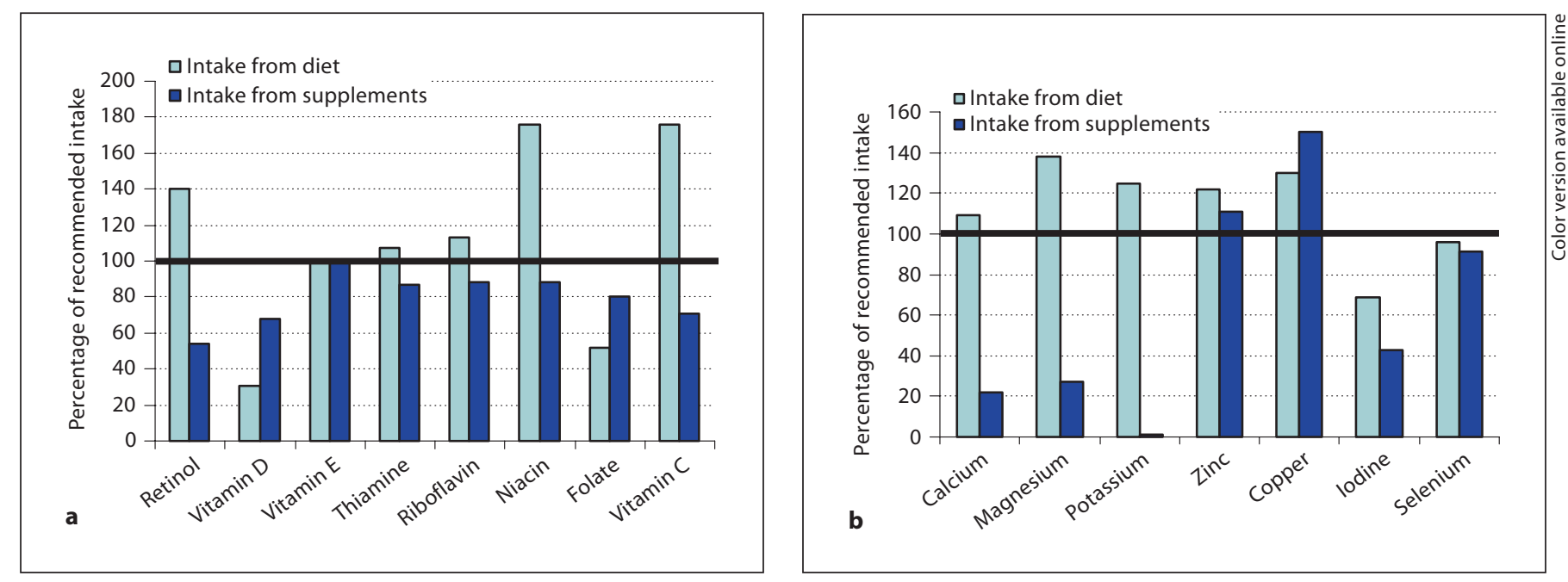

Fig. 1. a Median intake of vitamins from diet and supplements in percentage of recommended intake among supplement users. b Median intake of minerals from diet and supplements in percentage of recommended intake among supplement users.

ber and of all the vitamins and minerals than supplement users (table 4). However, the mean differences were small. Median intakes of the nutrients from diet alone were within the recommendations, except for vitamin $\mathrm{D}$, folate, iron and iodine in both groups.

Daily nutrient intake among women in the entire cohort, and including the contribution from dietary supplements, showed that $63 \%$ of the women in the MoBa cohort did not reach the recommended intake of vitamin $\mathrm{D}$ of $10 \mu \mathrm{g} /$ day and $12 \%$ did not reach the lower level of 2.5 $\mu \mathrm{g} /$ day (table 5 ). While $45 \%$ of the women among vitamin D supplement users did not reach the recommended intake, $99 \%$ of supplement nonusers did not reach the recommended intake. The upper intake level of vitamin $\mathrm{D}$ of $50 \mu \mathrm{g} /$ day was exceeded by $142(0.35 \%)$ of the women. Total intake of vitamin D was significantly lower in overweight/obese women compared with normal-weight women $(8.9 \pm 8.3$ and $11.1 \pm 9.6 \mu \mathrm{g} /$ day, respectively; $\mathrm{p}<0.001)$. Among folic acid supplement users, $34 \%$ did not reach the recommended intake of $500 \mu \mathrm{g} /$ day and among folic acid supplement nonusers, $97 \%$ did not reach the recommended intake. The intake of folic acid from dietary supplements exceeded the upper intake level of $1,000 \mu \mathrm{g} /$ day in $325(0.8 \%)$ of the women. Among iodine supplement users, $28 \%$ did not reach the recommended intake, and among supplement nonusers this figure was $80 \%$. The upper daily intake level for iodine (600 $\mu \mathrm{g} /$ day) was exceeded by $117(0.3 \%)$ of the participating women. $5 \%$ of vitamin A supplement users did not reach the rec- ommendations, while $30 \%$ of vitamin A supplement nonusers did not reach the recommended intake. For retinol, 1,549 (3.9\%) women exceeded the upper safe level of 3,000 $\mu \mathrm{g} / \mathrm{day}$, and $87 \%$ of these were retinol supplement users. Mean (SD) intake among the women who exceeded the upper safe level was $3,830 \mu \mathrm{g}(940 \mu \mathrm{g})$ with a median intake of 3,510 $\mu \mathrm{g}$ per day. An intake of more than 3,000 $\mu \mathrm{g} /$ day from supplements was only exceeded by 30 women $(0.07 \%$ of the subjects), and none of the women took retinol as a single-nutrient supplement. Zinc intake exceeded the upper intake level of $25 \mathrm{mg}$ /day in 3,707 (9\%) of the participants, and of these $99.6 \%$ got their zinc from multivitamin mineral supplements. The intake of the remaining nutrients did not give rise to concern.

\section{Discussion}

Nutritional advice to pregnant women in Norway consists of recommendations to take vitamin D supplements in the winter season and folic acid 1 month preconceptionally and 3 months into pregnancy. Our study suggests that the recommended dietary intake of these nutrients will not be reached without supplementation. The prevalence of supplement use found in this study is in accordance with two recent studies, where $85 \%$ of the pregnant women took some type of supplement in Finland [23], and $70 \%$ of pregnant women in Switzerland reported use of some sort of vitamin and mineral supplement [24]. 
Table 4. Nutrient intake from diet among SUs and NSUs

\begin{tabular}{|c|c|c|c|c|}
\hline & \multicolumn{2}{|c|}{ SUs $(n=32,653)$} & \multicolumn{2}{|l|}{ NSUs $(\mathrm{n}=7,455)$} \\
\hline & mean $(\mathrm{SD})$ & median (P5, P95) & mean $(\mathrm{SD})$ & median (P5, P95) \\
\hline Energy, kcal & $2,334(612)$ & $2,250(1,474,3,486)^{*}$ & $2,317(654)$ & $2,220(1,410,3,592)$ \\
\hline Protein, $g$ & $87(21)$ & $85(57,126)^{*}$ & $85(22)$ & $82(54,126)$ \\
\hline $\mathrm{E} \%{ }^{1}$ & $15.1(2.1)$ & $15.1(11.9,18.7)$ & $14.9(2.2)$ & $14.9(11.4,18.7)$ \\
\hline Fat, $g$ & $80(24)$ & $77(48,126)$ & $80(26)$ & $76(46,129)$ \\
\hline $\mathrm{E} \%$ & $31.0(4.6)$ & $31.0(23.6,38.5)$ & $31.3(4.8)$ & $31.2(23.4,39.1)$ \\
\hline Carbohydrates & $314(93)$ & $301(187,488)$ & $312(100)$ & $296(178,503)$ \\
\hline $\mathrm{E} \%$ & $53.6(4.8)$ & $53.6(46.0,61.6)$ & $53.4(5.2)$ & $53.4(45.2,62.3)$ \\
\hline EPA, g & $0.16(0.17)$ & $0.11(0.02,0.49)$ & $0.15(0.19)$ & $0.10(0.02,0.48)$ \\
\hline DHA, g & $0.26(0.25)$ & $0.19(0.06,0.70)$ & $0.25(0.26)$ & $0.18(0.05,0.70)$ \\
\hline $\mathrm{n}-3$ fatty acids, $g$ & $2.12(0.91)$ & $1.94(1.04,3.82)$ & $2.09(0.95)$ & $1.90(0.99,3.89)$ \\
\hline Retinol, $\mu g$ & $871(658)$ & $673(241,2,180)^{*}$ & $858(686)$ & $637(222,2,185)$ \\
\hline Beta-carotene, $\mu g$ & $2,621(1,808)$ & $2,043(895,6,025)^{*}$ & $2,483(1,826)$ & $1,906(787,6,040)$ \\
\hline Retinol eq., $\mu \mathrm{g}$ & $1,302(751)$ & $1,119(484,2,756)^{*}$ & $1,265(773)$ & $1,061(443,2,750)$ \\
\hline Vitamin $\mathrm{D}, \mu \mathrm{g}$ & $3.5(2.5)$ & $3.1(1.0,7.1)^{*}$ & $3.5(2.7)$ & $3.0(0.9,7.1)$ \\
\hline Vitamin E, mg & $11(4)$ & $10(6,18)^{*}$ & $10(4)$ & $9(5,18)$ \\
\hline Thiamine, mg & $1.6(0.4)$ & $1.6(0.9,2.4)^{*}$ & $1.5(0.5)$ & $1.4(0.9,2.3)$ \\
\hline Riboflavin, mg & $1.9(0.7)$ & $1.8(1.0,3.3)^{*}$ & $1.9(0.7)$ & $1.8(0.9,3.2)$ \\
\hline Niacin, mg & $30.5(6.9)$ & $29.8(6.9,20.6)^{*}$ & $29.7(7.1,19.6)$ & $29.0(19.6,42.5)$ \\
\hline Folate, $\mu \mathrm{g}$ & $275(95)$ & $260(15,448)^{*}$ & $260(99)$ & $244(136,439)$ \\
\hline Vitamin $\mathrm{B}_{12}, \mu \mathrm{g}$ & $6.1(2.8)$ & $5.5(2.7,11.3)^{*}$ & $6.0(2.9)$ & $5.3(2.5,11.5)$ \\
\hline Vitamin $\mathrm{B}_{6}, \mathrm{mg}$ & $1.5(0.4)$ & $1.5(0.9,2.3)^{*}$ & $1.5(0.5)$ & $1.4(0.9,2.3)$ \\
\hline Vitamin $\mathrm{C}, \mathrm{mg}$ & $167(91)$ & $150(59,338)^{*}$ & $160(98)$ & $138(51,348)$ \\
\hline Calcium, mg & $1,053(426)$ & $982(497,1,843)^{*}$ & $1,007(435)$ & $927(443,1,854)$ \\
\hline Magnesium, mg & $401(113)$ & $387(22,610)^{*}$ & $383(116)$ & $367(223,595)$ \\
\hline Potassium, $\mathrm{g}$ & $4.0(1.1)$ & $3.9(2.5,6.1)^{*}$ & $3.9(1.2)$ & $3.7(2.3,6.0)$ \\
\hline Iron, mg & $11.3(3.4)$ & $10.9(6.6,17.6)^{*}$ & $10.8(3.4)$ & $10.3(6.1,17.1)$ \\
\hline Zinc, $\mathrm{mg}$ & $11.3(3.0)$ & $11.0(7.1,16.8)^{*}$ & $10.6(3.0)$ & $11.0(6.6,16.6)$ \\
\hline Copper, mg & $1.4(0.4)$ & $1.3(0.8,2.1)^{*}$ & $1.3(0.8)$ & $1.3(0.8,2.1)$ \\
\hline Iodine, $\mu \mathrm{g}$ & $132(62)$ & $122(52,247)^{*}$ & $127(66)$ & $116(45,249)$ \\
\hline Selenium, $\mu \mathrm{g}$ & $54(15)$ & $53(34,81)^{*}$ & $53(15)$ & $51(31,81)$ \\
\hline
\end{tabular}

${ }^{*} \mathrm{p}<0.001$ between SUs and NSUs. ${ }^{1}$ Energy percentage.

Furthermore, the supplement users were higher educated, nonsmoking, pregnant for the first time and had a low to normal prepregnancy body weight, all findings also found in several other studies [23, 25-27]. The reduced use of dietary supplements and thus intake of several nutrients among the obese women may contribute to the higher frequency of adverse pregnancy outcomes in this group [28].

By far the most commonly reported supplements were cod liver/fish oils which might be explained by the Norwegians' long-standing tradition of cod-liver oil use to cover vitamin $\mathrm{D}$ needs. In addition to the growing evidence for beneficial effects of n-3 fatty acids, the use of fish oil capsules has increased. The high frequency of $n-$
3 fatty acid supplementation is probably unique for this study, because in a comparable study from Denmark only $4.3 \%$ of the participants reported use of fish oil supplements [29]. In Iceland, where a historical tradition of codliver oil consumption also exists, only $23 \%$ of healthy pregnant women reported a regular intake [30]. In accordance with the cod liver/fish oil supplementation, most of the intake of EPA and DHA came from dietary supplementation, which contributed $17 \%$ of the total $n-3$ fatty acid intake.

It is surprising that even though most of the participants in MoBa used some kind of vitamin D supplementation, as many as $63 \%$ did not reach the recommended intake of $10 \mu \mathrm{g} / \mathrm{day}$, and $12 \%$ did not reach the lower in- 
Table 5. Daily nutrient intake from diet and supplements among 40,108 women in MoBa

\begin{tabular}{|c|c|c|c|c|c|c|c|c|c|}
\hline \multirow[t]{2}{*}{ Nutrient } & \multirow[t]{2}{*}{ Mean } & \multirow[t]{2}{*}{ SD } & \multicolumn{5}{|c|}{ Percentiles } & \multirow{2}{*}{$\begin{array}{l}\text { Percent below } \\
\text { recommended } \\
\text { intake (NNR) }\end{array}$} & \multirow{2}{*}{$\begin{array}{l}\text { Percent below } \\
\text { lower level of } \\
\text { intake (NNR) }\end{array}$} \\
\hline & & & $5 \%$ & $25 \%$ & $50 \%$ & $75 \%$ & $95 \%$ & & \\
\hline Energy, kcal & 2,352 & 623 & 1,479 & 1,918 & 2,269 & 2,701 & 3,532 & & \\
\hline EPA, g & 0.4 & 0.8 & 0.03 & 0.10 & 0.21 & 0.54 & 1.32 & & \\
\hline DHA, g & 0.5 & 0.8 & 0.07 & 0.18 & 0.32 & 0.73 & 1.65 & & \\
\hline $\mathrm{E} \%$ from $\mathrm{EPA}+\mathrm{DHA}$ & 0.4 & 0.5 & 0.04 & 0.11 & 0.21 & 0.50 & 1.21 & & \\
\hline Total $n-3$ fatty acids, $g$ & 2.7 & 1.4 & 1.13 & 1.70 & 2.35 & 3.47 & 5.42 & & \\
\hline E\% n-3 fatty acids & 1.1 & 0.5 & 0.51 & 0.71 & 0.92 & 1.29 & 2.1 & $57(1)$ & \\
\hline Retinol, $\mu \mathrm{g}$ & 1,259 & 831 & 321 & 659 & 1,084 & 1,638 & 2,804 & & \\
\hline Beta-carotene, $\mu \mathrm{g}$ & 2,751 & 2,370 & 885 & 1,460 & 2,079 & 3,355 & 6,520 & & \\
\hline Retinol eq., $\mu \mathrm{g}$ & 1,712 & 962 & 596 & 1,045 & 1,528 & 2,157 & 3,432 & $13(800)$ & $1(400)$ \\
\hline Vitamin $D, \mu g$ & 10.7 & 9.5 & 1.6 & 3.9 & 7.3 & 14.5 & 29.9 & $63(10)$ & $12(2.5)$ \\
\hline Vitamin E, mg & 21 & 18 & 7 & 11 & 17 & 26 & 45 & $22(10)$ & $\sim 0(3)$ \\
\hline Thiamine, mg & 2.6 & 7.1 & 1.0 & 1.4 & 2.4 & 2.7 & 4.2 & $31(1.5)$ & $\sim 0(0.5)$ \\
\hline Riboflavin, mg & 3.1 & 7.1 & 1.1 & 1.7 & 2.4 & 3.3 & 5.1 & $22(1.6)$ & $4(0.8)$ \\
\hline Niacin, mg & 37.0 & 15.3 & 21.6 & 27.9 & 34.1 & 43.1 & 59.0 & $0.5(17)$ & $\sim 0(9)$ \\
\hline Folate, $\mu \mathrm{g}$ & 481 & 277 & 168 & 267 & 413 & 655 & 929 & $57(500)$ & $0.2(100)$ \\
\hline Vitamin $\mathrm{B}_{12}, \mu \mathrm{g}$ & 8.8 & 23.2 & 2.9 & 4.6 & 6.4 & 9.0 & 15.4 & $0.8(2)$ & $\sim 0(1)$ \\
\hline Vitamin $\mathrm{B}_{6}, \mathrm{mg}$ & 2.9 & 7.5 & 1.0 & 1.4 & 1.9 & 3.1 & 5.3 & $32(1.5)$ & $1(0.8)$ \\
\hline Vitamin C, mg & 202 & 120 & 65 & 123 & 178 & 251 & 412 & $10(85)$ & $\sim 0(10)$ \\
\hline Calcium, mg & 1,076 & 444 & 501 & 772 & 440 & 1,300 & 1,902 & $39(900)$ & $2(400)$ \\
\hline Magnesium, mg & 416 & 127 & 244 & 329 & 398 & 483 & 646 & $11(280)$ & NG \\
\hline Potassium, g & 4.0 & 1.1 & 2.4 & 3.2 & 3.9 & 4.6 & 6.1 & $21(3.1)$ & $0.1(1.6)$ \\
\hline Iron, mg & 25.0 & 33.8 & 7.1 & 10.3 & 14.7 & 24.4 & 99.8 & $51(15)$ & $0.4(5)$ \\
\hline Zinc, mg & 14.7 & 7.7 & 7.3 & 9.9 & 12.4 & 17.6 & 28.0 & $16(9)$ & $\sim 0$ (4) \\
\hline Copper, mg & 1.8 & 1.0 & 0.9 & 1.2 & 1.5 & 2.1 & 3.5 & $11(1)$ & $\sim 0(0.4)$ \\
\hline Iodine, $\mu \mathrm{g}$ & 163 & 91 & 56 & 100 & 142 & 207 & 326 & $64(175)$ & $10(70)$ \\
\hline Selenium, $\mu \mathrm{g}$ & 71 & 37 & 35 & 48 & 60 & 85 & 134 & $40(55)$ & $0.1(20)$ \\
\hline
\end{tabular}

Intake is compared with the NNR. The recommended values for the nutrients are shown in parentheses. NG = Not given. Dietary folate is calculated according to Yates et al. [43].

take limit of $2.5 \mu \mathrm{g} /$ day. Similar results were reported in a Finnish pregnancy study where supplements contributed $74 \%$ of the vitamin D intake among supplement users but $85 \%$ did not reach the recommended intake [23]. In the validation study of the MoBa FFQ, a positive correlation between vitamin $\mathrm{D}$ intake and 25-hydroxyvitamin D status was found [19]. Furthermore, the study showed that almost $20 \%$ of the women had a moderate vitamin D hypovitaminosis (plasma concentration of 25hydroxyvitamin $\mathrm{D}<40 \mathrm{nmol} / \mathrm{l}$ ) which actualizes the importance of vitamin D supplementation. Low maternal vitamin $\mathrm{D}$ status has been shown to be associated with reduced intrauterine long bone growth, shorter gestation, lower birth weight and reduced bone mass at 9 years of age [31-33]. With vitamin D's ability to modulate the immune system, it has been hypothesized that vitamin $\mathrm{D}$ status is negatively associated with preeclampsia [34], and low circulating 1,25-dihydroxyvitamin $\mathrm{D}$ has also been reported in women with preeclampsia [35].

The frequency of reported folic acid supplementation during pregnancy is higher than the $52 \%$ reported earlier from MoBa [26]. It might be explained by use of different data sources, but hopefully the explanation is that there has been an increase in use over the years as a result of intensified governmental information to the public. The data in the earlier study covered women enrolled in $\mathrm{MoBa}$ between 2000 and 2003, while the data in this report cover women enrolled between 2002 and 2005. This study confirms that supplementation is necessary to reach the recommended intake of $500 \mu \mathrm{g}$ of folate per day.

As many as $25 \%$ of the women had a total iodine intake below $100 \mu \mathrm{g} / \mathrm{day}$, and among iodine supplement 
nonusers only 1 in 5 reached the recommended intake. It has generally been reckoned that iodine status is satisfactory in Norwegians, although a fairly recent Norwegian study reported intakes comparable to those we found [36]. The low intake of iodine was confirmed by a low 24-hour urinary iodine excretion in iodine supplement nonusers in MoBa [19]. Further studies of iodine status in pregnancy should be considered because increased demand for iodine throughout pregnancy has been documented [37], and even mild or subclinical maternal hypothyroidism during pregnancy can impair maternal health and the development of the newborn $[38,39]$.

Iron intake from supplementation is difficult to evaluate because no general recommendation is given for iron supplementation in pregnancy in Norway. A low iron status will be diagnosed by serum ferritin and the physician will then prescribe an iron supplement. Prescription of iron will probably be considered as a drug and not as a dietary supplement by the women. Most certainly, we have missed some information about iron intake this way. Our results differ significantly from Finnish and Greek data, both countries having general recommendations for iron supplementation to pregnant women [23, 40]. Still, 22\% of the MoBa participants record use of an iron supplement and a further $25 \%$ received iron through a combination formula.

Almost $4 \%$ of the study population exceeded the upper safe level of 3,000 $\mu \mathrm{g} / \mathrm{day}$ of retinol. However, most of the retinol came from the combination of food intake and supplements. To our knowledge, only the intake of more than 3,000 $\mu \mathrm{g} /$ day of retinol from supplements has been shown to increase the risk of malformation of the fetus, and the number of women who exceeded this intake was within the margin of error registration [41].

Zinc was the nutrient most frequently exceeding the upper safe intake level, and almost all were zinc supplement users. An explanation for this is that $25 \mathrm{mg}$ zinc is allowed in dietary supplements in Norway. However, intakes up to $50 \mathrm{mg}$ /day have not been shown to have any adverse health effects [42], and that amount was only registered in a few participants which again is within the margin of error registration.

The method used to calculate the nutrient intake from the dietary supplements has been validated in an earlier study [19]. However, the uncertainty with the imputation and the difficulties to obtain nutrient content for some supplements might have had an impact on the results. Though we had problems collecting nutrient information for some supplements, these were mostly herb supple- ments, which were used by one or just a few participants.

A participation rate of $41.6 \%$ in MoBa might imply a selection bias, and it is likely that there is a socioeconomic gradient in favor of a better diet that influences the observed dietary pattern [20]. However, the basic characteristics of the women, such as age and parity, and birth outcomes like gestational age, prevalence of preterm births and birth weight are not different between the study population and the total pregnancy population in Norway [16]. The aim of MoBa is to estimate the association between exposure and disease in nested case-control studies, and hence selection bias is of less concern [16].

In conclusion, dietary supplements were used by $81.4 \%$ of the women in MoBa, and were favored by older, normal-weight, nonsmoking, higher educated women carrying their first child. The contribution of supplements was substantial to vitamin $\mathrm{D}, \mathrm{DHA}, \mathrm{EPA}$, vitamin $\mathrm{B}_{6}$, folate, copper and iron intake among the users. However, even though intake of vitamin $\mathrm{D}$, folate and iodine improved with use of supplements, the recommended intake was not reached for a substantial number of the participants. There should be more public awareness of the importance of iodine and vitamin $\mathrm{D}$ for pregnant women.

\section{Acknowledgements}

We want to acknowledge Marit Hilsen, Olaug Siqveland, Elise Birkeland and Linn Helene Stølen for valuable contribution to the dietary supplement database. The Norwegian Mother and Child Cohort Study is supported by the Norwegian Ministry of Health, NIH/NIEHS (grant N01-ES-85433), NIH/NINDS (grant 1 UO1 NS 047537-01), and the Norwegian Research Council/FUGE (grant 151918/S10).

References

1 Godfrey K, Robinson S, Barker DJ, Osmond C, Cox V: Maternal nutrition in early and late pregnancy in relation to placental and fetal growth. BMJ 1996;312:410-414.

2 Godfrey K, Robinson S: Maternal nutrition, placental growth and fetal programming. Proc Nutr Soc 1998;57:105-111.

3 Oken E, Ning Y, Rifas-Shiman SL, Rich-Edwards JW, Olsen SF, Gillman MW: Diet during pregnancy and risk of preeclampsia or gestational hypertension. Ann Epidemiol 2007;17:663-668.

-4 Barker DJ, Gluckman PD, Godfrey KM, Harding JE, Owens JA, Robinson JS: Fetal nutrition and cardiovascular disease in adult life. Lancet 1993;341:938-941. 
5 Clausen T, Slott M, Solvoll K, Drevon CA, Vollset SE, Henriksen T: High intake of energy, sucrose, and polyunsaturated fatty acids is associated with increased risk of preeclampsia. Am J Obstet Gynecol 2001;185: 451-458.

6 MRC Vitamin Study Research Group: Prevention of neural tube defects: results of the Medical Research Council Vitamin Study. Lancet 1991;338:131-137.

7 Milman N, Bergholt T, Byg KE, Eriksen L, Graudal N: Iron status and iron balance during pregnancy. A critical reappraisal of iron supplementation. Acta Obstet Gynecol Scand 1999;78:749-757.

$\checkmark 8$ Helland IB, Smith L, Saarem K, Saugstad OD, Drevon CA: Maternal supplementation with very-long-chain $n-3$ fatty acids during pregnancy and lactation augments children's IQ at 4 years of age. Pediatrics 2003;111:e39e44.

9 Oken E, Kleinman KP, Olsen SF, Rich-Edwards JW, Gillman MW: Associations of seafood and elongated $\mathrm{n}-3$ fatty acid intake with fetal growth and length of gestation: results from a US pregnancy cohort. Am J Epidemiol 2004; 160:774-783.

10 Jensen CL: Effects of n-3 fatty acids during pregnancy and lactation. Am J Clin Nutr 2006;1452S-1457S.

$\checkmark 11$ Morris CD, Jacobson SL, Anand R, Ewell MG, Hauth JC, Curet LB, Catalano PM, Sibai BM, Levine RJ: Nutrient intake and hypertensive disorders of pregnancy: evidence from a large prospective cohort. Am J Obstet Gynecol 2001;184:643-651.

-12 Rumbold AR, Crowther CA, Haslam RR, Dekker GA, Robinson JS: Vitamins C and E and the risks of preeclampsia and perinatal complications. N Engl J Med 2006;354:17961806.

13 Maats FH, Crowther CA: Patterns of vitamin, mineral and herbal supplement use prior to and during pregnancy. Aust $\mathrm{N} Z \mathrm{Z} \mathrm{J} \mathrm{Ob-}$ stet Gynaecol 2002;42:494-496.

-14 Tsui B, Dennehy CE, Tsourounis C: A survey of dietary supplement use during pregnancy at an academic medical center. Am J Obstet Gynecol 2001;185:433-437.

-15 Radimer KL: National nutrition data: contributions and challenges to monitoring dietary supplement use in women. J Nutr 2003; 133:2003S-2007S.

16 Magnus P, Irgens LM, Haug K, Nystad W, Skjaerven R, Stoltenberg C, MoBa Study Group: Cohort profile: The Norwegian Mother and Child Cohort Study (MoBa). Int J Epidemiol 2006;35:1146-1150.

17 NNR Project Group: Nordic Nutrition Recommendations 2004, ed 4. Copenhagen, Nordic Council of Ministers, 2004.

-18 Brantsæeter AL, Haugen M, Alexander J, Meltzer HM: Validity of a new Food Frequency Questionnaire for pregnant women in the Norwegian Mother and Child Cohort Study (MoBa). Matern Child Nutr 2008;4: 28-43.
9 Brantsæter AL, Haugen M, Hagve T-A, Aksnes L, Rasmussen SE, Julshamn K, Alexander J, Meltzer HM: Self-reported dietary supplement use is confirmed by biological markers in the Norwegian Mother and Child Cohort Study (MoBa). Ann Nutr Metab 2007;51:146-154.

20 Meltzer HM, Brantsæter AL, Ydersbond T, Alexander J, Haugen M, The MoBa Dietary Support Group: Methodological challenges when monitoring the diet of pregnant women in a large study; experiences from the Norwegian Mother and Child Cohort Study. Matern Child Nutr 2008;4:14-27.

21 Lauritzen J: FoodCalc. www.ibt.ku.dk/jesper/FoodCalc/Default.htm; accessed October 2005 .

22 Rimestad AH, Borgerjordet A, Vesterhus KN, Sygnestveit K, Løken EB, Trygg K, Pollestad L, Lund-Larsen K, Omholt-Jensen G, Nordbotten A: The Norwegian Food Table. Oslo, Statens Råd for Ernæring og Fysisk Aktivitet, Statens Næringsmiddeltilsyn, Institutt for Ernæringsforskning, 2005.

23 Arkkola T, Uusitalo U, Pietikainen M, Metsala J, Kronberg-Kippila C, Erkkola M, Veijola R, Knip M, Virtanen SM, Ovaskainen ML: Dietary intake and use of dietary supplements in relation to demographic variables among pregnant Finnish women. Br J Nutr 2006;96:913-920.

24 Hess SY, Zimmermann MB, Torresani T, Burgi H, Hurrell RF: Monitoring the adequacy of salt iodization in Switzerland: a national study of school children and pregnant women. Eur J Clin Nutr 2001;55:162-166.

25 Braekke K, Staff AC: Periconceptional use of folic acid supplements in Oslo. Acta Obstet Gynecol Scand 2003;82:620-627.

26 Nilsen RM, Vollset SE, Gjessing HK, Magnus P, Meltzer HM, Haugen M, Ueland PM: Patterns and predictors of folic acid supplement use among pregnant women: the Norwegian Mother and Child Cohort Study. Am J Clin Nutr 2006;84:1134-1141.

27 Forster DA, Wills G, Denning A, Bolger M: The use of folic acid and other vitamins before and during pregnancy in a group of women in Melbourne, Australia. Midwifery DOI 10.1016/i.midw2007.01.019.

28 Cnattingius S, Bergstrom R, Lipworth L, Kramer MS: Prepregnancy weight and the risk of adverse pregnancy outcomes. N Engl J Med 1998;338:147-152.

29 Olsen SF, Mikkelsen TB, Knudsen VK, Orozova-Bekkevold I, Halldorsson TI, Strom M, Osterdal ML: Data collected on maternal dietary exposures in the Danish National Birth Cohort. Paediatr Perinat Epidemiol 2007;21: 76-86.

30 Olafsdottir AS, Skuladottir GV, Thorsdottir I, Hauksson A, Thorgeirsdottir H, Steingrimsdottir L: Relationship between high consumption of marine fatty acids in early pregnancy and hypertensive disorders in pregnancy. BJOG 2006;113:301-309.
31 Morley R, Carlin JB, Pasco JA, Wark JD: Maternal 25-hydroxyvitamin $\mathrm{D}$ and parathyroid hormone concentrations and offspring birth size. J Clin Endocrinol Metab 2006;91: 906-912.

32 Mannion CA, Gray-Donald K, Koski KG: Association of low intake of milk and vitamin D during pregnancy with decreased birth weight. CMAJ 2006;174:1273-1277.

33 Javaid MK, Crozier SR, Harvey NC, Gale CR, Dennison EM, Boucher BJ, Arden NK, Godfrey KM, Cooper C: Maternal vitamin D status during pregnancy and childhood bone mass at age 9 years: a longitudinal study. Lancet 2006;367:36-43.

34 Hypponen E: Vitamin D for the prevention of preeclampsia? A hypothesis. Nutr Rev 2005;63:225-232.

35 Halhali A, Villa AR, Madrazo E, Soria MC, Mercado E, Diaz L, Avila E, Garabedian M, Larrea F: Longitudinal changes in maternal serum 1,25-dihydroxyvitamin $\mathrm{D}$ and insulin like growth factor I levels in pregnant women who developed preeclampsia: comparison with normotensive pregnant women. J Steroid Biochem Mol Biol 2004;89-90: 553-556.

36 Dahl L, Meltzer HM, Opsahl JL, Julshamn K: Iodine intake and status in two groups of Norwegians. Scand J Nutr 2003;47:170-178.

$>37$ Glinoer D: The regulation of thyroid function during normal pregnancy: importance of the iodine nutrition status. Best Pract Res Clin Endocrinol Metab 2004;18:133-152.

38 Delange F: Iodine deficiency in Europe and its consequences: an update. Eur J Nucl Med Mol Imaging 2002;29(suppl 2):S404-S416.

39 Glinoer D: Clinical and biological consequences of iodine deficiency during pregnancy. Endocr Dev 2007;10:62-85.

40 Petrakos G, Panagopoulos P, Koutras I, Kazis A, Panagiotakos D, Economou A, Kanellopoulos N, Salamalekis E, Zabelas A: A comparison of the dietary and total intake of micronutrients in a group of pregnant Greek women with the Dietary Reference Intakes. Eur J Obstet Gynecol Reprod Biol 2006;127: 166-171.

41 Rothman KJ, Moore LL, Singer MR, Nguyen US, Mannino S, Milunsky A: Teratogenicity of high vitamin A intake. N Engl J Med 1995; 333:1369-1373.

42 Bonham M, O’Connor JM, McAnena LB, Walsh PM, Downes CS, Hannigan BM, Strain JJ: Zinc supplementation has no effect on lipoprotein metabolism, hemostasis, and putative indices of copper status in healthy men. Biol Trace Elem Res 2003;93: 75-86.

43 Yates AA, Schlicker SA, Suitor CW: Dietary Reference Intakes: the new basis for recommendations for calcium and related nutrients, B vitamins, and choline. J Am Diet Assoc 1998;98:699-706. 